This is the peer reviewed version of the following article:

Troyano J ., Castillo O., Martínez J.I., Fernández-Moreira V., Ballesteros Y., Maspoch D., Zamora F., Delgado S.. Reversible Thermochromic Polymeric Thin Films Made of Ultrathin 2D Crystals of Coordination Polymers Based on Copper(I)-Thiophenolates. Advanced Functional Materials, (2018). 28. 1704040: - . 10.1002/adfm.201704040,

which has been published in final form at https: //dx.doi.org/10.1002/adfm.201704040. This article may be used for non-commercial purposes in accordance with Wiley Terms and Conditions for Use of Self-Archived Versions. 


\title{
Reversible Thermochromic Polymeric Thin Films Made of Ultrathin 2D Crystals of Coordination Polymers Based on Copper(I)-Thiophenolates
}

Javier Troyano, a,b Oscar Castillo, ${ }^{\mathrm{c}}$ José I. Martínez, ${ }^{\mathrm{d}}$ Vanesa Fernández-Moreira, e Yolanda Ballesteros, ${ }^{\dagger}$ Daniel Maspoch, ${ }^{* b, g}$ Félix Zamora, ${ }^{* a, h, i, j}$ Salome Delgado ${ }^{* a, i}$

\author{
a) Departamento de Química Inorgánica Universidad Autónoma de Madrid 28049 Madrid, Spain \\ b) Catalan Institute of Nanoscience and Nanotechnology (ICN2) CSIC and the Barcelona Institute of Science and Technology Campus UAB, \\ Bellaterra 08193, Barcelona, Spain \\ c) Departamento de Química Inorgánica Universidad del País Vasco UPV/EHU, Apartado 644, E-48080 Bilbao, Spain \\ d) Departamento de Nanoestructuras, Superficies Recubrimientos y Astrofísica Molecular Instituto de Ciencia de Materiales de Madrid \\ (ICMM-CSIC) 28049 Madrid, Spain \\ e) Departamento de Química Inorgánica Instituto de Síntesis Química y Catálisis Homogénea (ISQCH) CSIC-Universidad de Zaragoza \\ Zaragoza 50009, Spain \\ f) Instituto de Investigación Tecnológica Departamento de Ingeniería Mecánica Universidad Pontificia Comillas 28015 Madrid, Spain \\ g) ICREA Pg. Lluís Companys 2308010 Barcelona, Spain \\ h) Condensed Matter Physics Center (IFIMAC) Universidad Autónoma de Madrid 28049 Madrid, Spain \\ i) Institute for Advanced Research in Chemical Sciences (IAdChem) Universidad Autónoma de Madrid 28049 Madrid, Spain \\ j) Instituto Madrileño de Estudios Avanzados en Nanociencia (IMDEA Nanociencia) Cantoblanco 28049, Madrid, Spain \\ E-mail: felix.zamora@uam.es; salome.delgado@uam.es; daniel.maspoch@icn2.cat
}

\begin{abstract}
A one-pot reaction between $\mathrm{Cu}\left(\mathrm{BF}_{4}\right)_{2} \cdot \mathrm{xH}_{2} \mathrm{O}$ and 4-mercaptobenzoic acid in acetone or methanol gives rise to the formation of lamellar microcrystals of two $\mathrm{Cu}(\mathrm{I})$-thiophenolatebased coordination polymers (CPs) with the formulas [CuCT $]_{n}(\mathbf{1})$ (CT = 4-carboxythiophenolate) and $[\mathrm{CuMCT}]_{n}(2) \quad(\mathrm{MCT}=$ 4-methoxycarbonyl-thiophenolate). Both 1 and 2show a reversible luminescent thermochromic behavior upon cooling, changing their color from pale yellow to green to orange in the case of 1, and from pale orange to green in the case of $\mathbf{2}$. It is shown that the lamellar character of these crystals, which exhibit micrometer lateral dimensions and sub-micrometer/nanometer thicknesses, allows processing them with an organic polymer such as polyvinylidene difluoride (PVDF) to form thermochromic1@PVDF and 2@PVDF thin films. These thermal stimuli-responsive thin films are freestanding, free of macroscopic defects, and robust under mechanical bending stress, opening up the possibility to use them in, for example, 2D imaging sensor films.
\end{abstract}

\section{Introduction}

Luminescent films are very important for a wide variety of displays and optoelectronic devices, including light-emitting diodes, solar cells, photodetectors, flat-panel displays, and chemo/biosensors.[1] Among the luminescent materials, those exhibiting thermochromism are particularly attractive because of their potential use as temperature sensors.[2] A particular type of thermochromic materials is the family of $d^{10}$ transition metals complexes, due to the presence of metal-metal interactions with a closed-shell configuration. In these complexes, changes in color can be originated from an important shift of an emission band or the presence of two or more emission bands whose intensities fluctuate with temperature.[3] In this context, coordination polymers (CPs) bearing closed-shell $\mathrm{d}^{10}$ transition metals have recently been proposed as an alternative strategy to expand the variety of thermochromic materials.[4] In particular, those CPs based on $\mathrm{Cu}(\mathrm{I})$ seem to be appropriate because of their wide structural variety combined with brightly luminescence 
emission varying from blue to red light.[5] A specific type of robust CPs is built up from thiolates,[6] which those made of $\mathrm{Cu}(\mathrm{I}),[\mathrm{Cu}(\mathrm{SR})]_{n}(\mathrm{SR}=$ thiolate), which have recently shown interesting electrical and/or optical properties.[7] However, examples of $\mathrm{Cu}(\mathrm{I})$-CPs based on thiolate ligands with thermochromic properties are still very scarce.[8]

In addition, due to these special luminescence features and the increasing practical demand, efforts continue to expand industrial applications and the processing path of luminescent/thermochromic CPs. Particularly, the preparation of CPs as thin films is an area that has only recently been started but which can be relevant for many practical applications including chemical sensors, catalysis, and membranes.[1,9] CP thin films are expected to show some distinctive and eye-catching properties for the fabricated luminophores. Despite composite fabrication of CPs-organic hybrids is known,[10] integrating functional CPs as thin films is still very limited mainly due to their limited processability.[11] Very recently, for example, the integration of CPs within organic polymeric matrices has been achieved using colloidal 2D nanosheets of CPs, opening up an elegant route for making CP thin films that show improved gas separation properties.[12]

Following our research interest in the preparation of CPs based on organosulfur ligands and $\mathrm{d}^{10}$ metals ions,[13] herein we show that the direct synthesis between $\mathrm{Cu}\left(\mathrm{BF}_{4}\right)_{2} \cdot x \mathrm{H}_{2} \mathrm{O}$ and 4mercaptobenzoic acid (4-mba) in different organic solvents gives rise to the formation of two thermochromic CPs in the form of crystals with micrometer-size lateral dimensions and submicro-/nanometer thicknesses. The emission properties of these 2D CP crystals and their integration with polyvinylidene difluoride (PVDF) to form highly homogeneous composite thermochromic thin films have been studied. Theoretical calculations have been used in order to rationalize their emission.

\section{Results and Discussion}

\section{Synthesis and Structural Characterization}

Polycrystalline powder of [CuCT $]_{n}(\mathbf{1})$ was synthesized by a solvothermal reaction between $\mathrm{Cu}\left(\mathrm{BF}_{4}\right)_{2} \cdot x \mathrm{H}_{2} \mathrm{O}$ and 4-mba (1:2) in acetone (Scheme 1). Note here that the synthesis of 1 , as micropowder, was also reported by refluxing $\mathrm{Cu}_{2} \mathrm{O}$ and 4-mba in ethanol.[7] By replacing acetone by $\mathrm{MeOH}$ as the reaction media, we found the formation of polycrystalline $[\mathrm{CuMCT}]_{n}(2)$ due to the in situ esterification of the carboxylic group of 4-mba (Figures S1 and S2, Supporting Information). This esterification was confirmed by elemental analysis and Fourier transform infrared (FTIR) spectroscopy (Figures S3 and S4, Supporting Information). The carbonyl stretching frequency of 2 showed a shift to a higher energy $\left(1720 \mathrm{~cm}^{-1}\right)$ compared to the corresponding signal of the carboxyl group observed in $1\left(1682 \mathrm{~cm}^{-1}\right)$. This in situ esterification was further corroborated by isolating the diester of the oxidized form of 4-mba, bis- $p$-methoxycarbonyl-phenyl disulfide $\left[p-\left(\mathrm{CO}_{2} \mathrm{Me}\right) \mathrm{PhS}\right]_{2}$, as a by-product of this reaction (Table S1, Supporting Information). In fact, an analogous transition-metal-catalyzed esterification reaction[14] under solvothermal conditions of the isonicotinic acid in the presence of $\mathrm{Cul}$ in $\mathrm{EtOH}$ as solvent was also recently reported by us.[15] 


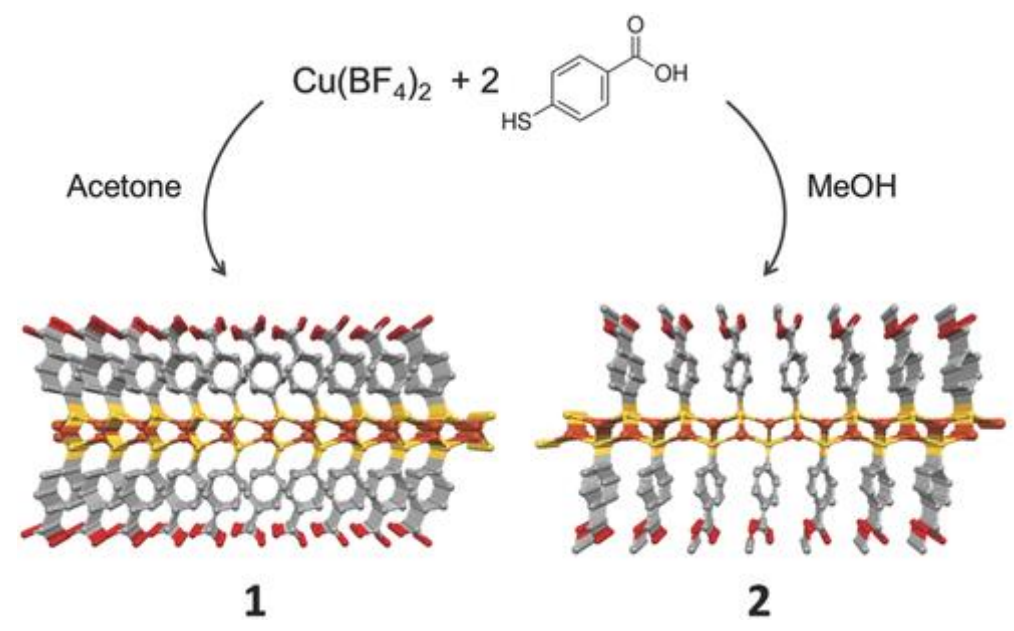

Scheme 1. Solvothermal reactions between $\mathrm{Cu}\left(\mathrm{BF}_{4}\right)_{2} \cdot \mathrm{xH}_{2} \mathrm{O}$ and 4-mercaptobenzoic acid (4-mba) at $120^{\circ} \mathrm{C}$ for $48 \mathrm{~h}$ in acetone and methanol to produce 1 and 2 , respectively.

Replacement of acetone by dimethylformamide (DMF) in the reaction of $\mathbf{1}$ allowed isolating crystals suitable for single-crystal $X$-ray analysis (Table S2, Supporting Information). Similarly, the solvothermal reaction $\left(140{ }^{\circ} \mathrm{C} / 20 \mathrm{~h}\right)$ between $\mathrm{Cu}\left(\mathrm{BF}_{4}\right)_{2} \cdot \mathrm{xH}_{2} \mathrm{O}$ and $(p-$ $\left.\left(\mathrm{CO}_{2} \mathrm{Me}\right) \mathrm{PhS}\right)_{2}(1: 1)$ in DMF led to the formation of crystals of 2 by in situ cleavage of $\mathrm{S} \square \mathrm{S}$ bond in $\left(p-\left(\mathrm{CO}_{2} \mathrm{Me}\right) \mathrm{PhS}\right)_{2}$ (Table S2, Supporting Information).

1 and 2 are almost isostructural to previously reported compound [CuHT]n[7] (HT = 4hydroxy-thiophenolate). They consists of layers based on fused $\mathrm{Cu}_{3} \mathrm{~S}_{3}$ rings with the copper atoms adopting a slightly distorted trigonal planar geometry with three $\mu_{3}$-bridging $S$ atoms of the thiolate ligands showing $S \square \mathrm{Cu} \square \mathrm{S}$ bond angles in the range of $103^{\circ}-130^{\circ}$ (Figures 1and 2, Table 1). The $\mathrm{Cu} \square \mathrm{S}$ distances are in the range of 2.24-2.30 $\AA$, which are comparable with those of neutral polymeric homoleptic $[\mathrm{Cu}(\mathrm{SPh}-p-\mathrm{X})]_{n}\left(\mathrm{X}=\mathrm{H}, \mathrm{CH}_{3}, \mathrm{OCH}_{3}\right.$, $\left.\mathrm{NO}_{2}, \mathrm{OH}\right)(2.24-2.35 \AA$ ).[7] These layers are completed by the functionalized phenyl moieties placed above and below the layer. However, the presence of different functional groups in the phenyl ring induces significant modifications in the $\mathrm{Cu}_{3} \mathrm{~S}_{3}$ rings conformation (half-chair for 1 vs twist-boat for 2), the thickness of the inorganic core of the 2D sheet ( 2.037 vs $2.163 \AA$ ), the dihedral angle between the phenyl rings inside the sheet (parallel vs $50^{\circ}$ ), and the supramolecular interactions that held together the layers (hydrogen bonding vs weak van der Waals interactions). Note here that, although $\pi-\pi$ stacking interactions are predominant in the packing of the layers in the analogous $[\mathrm{CuHT}]_{n}$, there is no experimental evidence of $\pi-\pi$ stacking interactions between the phenyl rings in $\mathbf{1}$ and $\mathbf{2}$. Layers in $\mathbf{1}$ are connected through the well-known complementary double hydrogen bond between adjacent carboxylic groups. On the other hand, esterification of the carboxylic residue in 2 precludes these interactions, meaning that layers are only sustained by means of weak van der Waals interactions. 


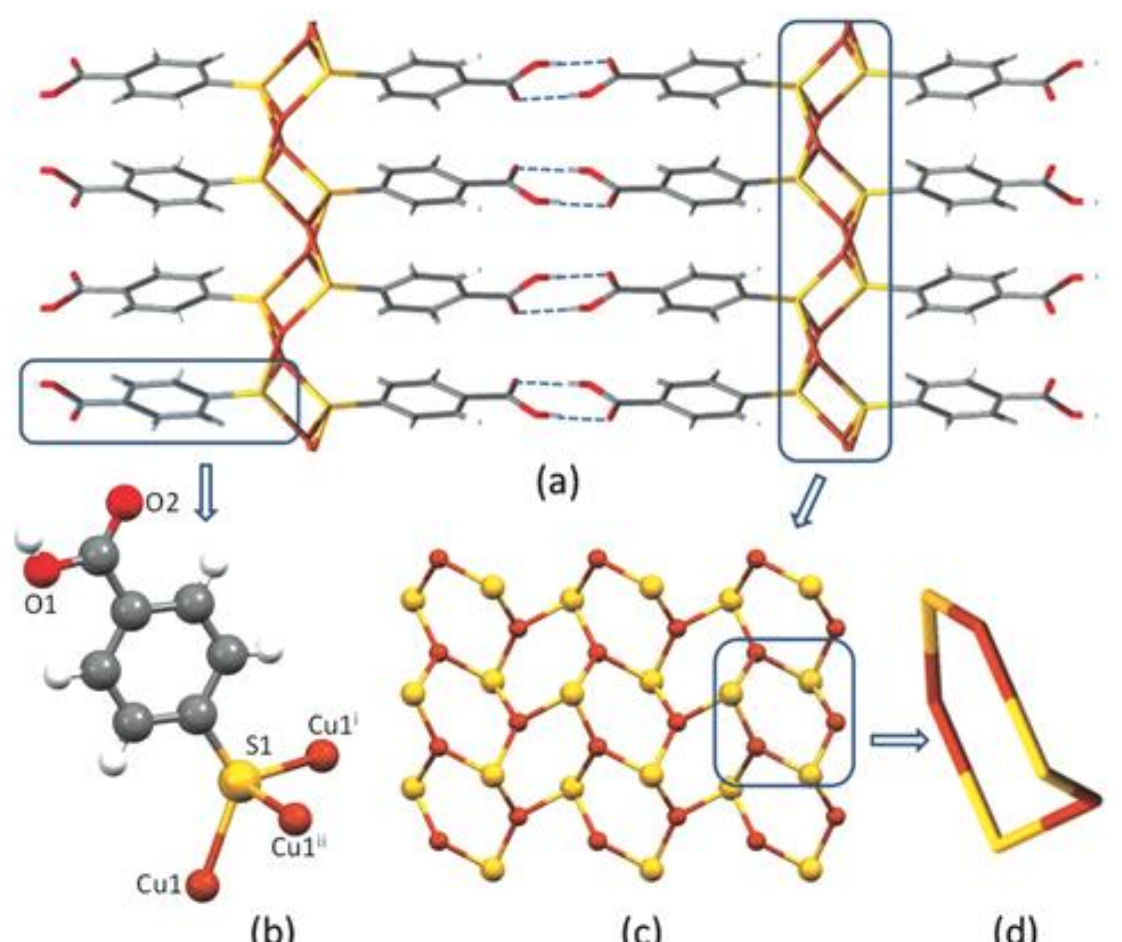

Figure 1. Crystal structure of 1 . Representations of a) crystal packing showing the complementary hydrogen bonding interactions (dashed lines); b) coordination mode of 4-mba ligand; c) Cu'-S sheet; and d) $\mathrm{Cu}_{3} \mathrm{~S}_{3}$ fused rings half-chair conformation.

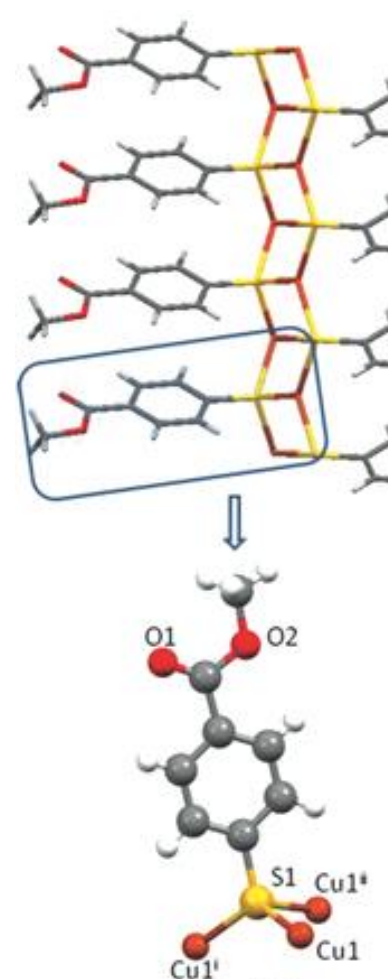

(b)

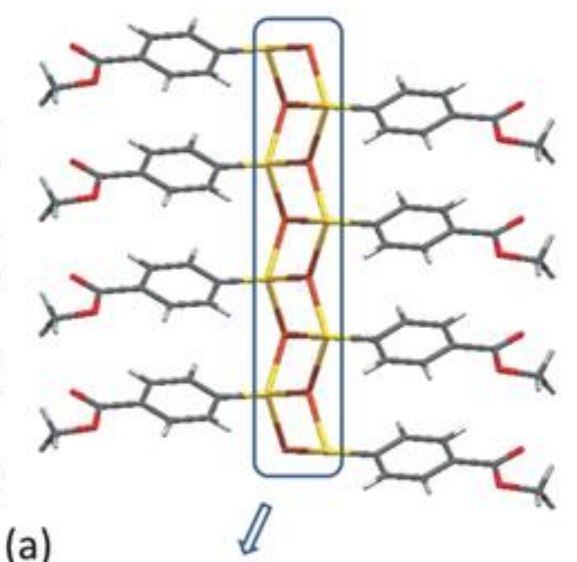

(a)

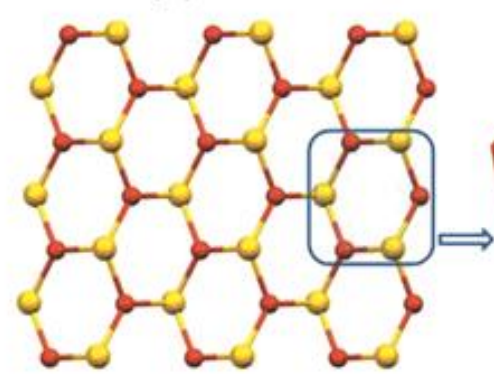

(c)

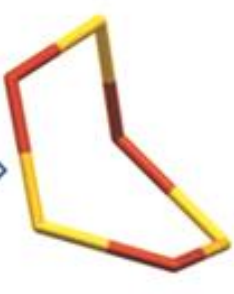

(d)

Figure 2. Crystal structure of 2. Representations of a) crystal packing; b) coordination mode of 4methoxycarbonyl-thiophenolate ligand; c) $\mathrm{Cu}^{\prime}-\mathrm{S}$ sheet; and d) $\mathrm{Cu}_{3} \mathrm{~S}_{3}$ fused rings twist-boat conformation. 
Table 1. Selected structural parameters $\left(\AA{ }^{\circ},{ }^{\circ}\right) \mathrm{S} \square \mathrm{Cu} \square \mathrm{S}$ bond angles and $\mathrm{Cu} \square \mathrm{S}$ and $\mathrm{Cu} \square \mathrm{Cu}$ distances and their average value for compounds 1 and 2

\begin{tabular}{|c|c|c|}
\hline & 1 $^{\text {a) }}$ & $2^{\text {a) }}$ \\
\hline Cu1-S1 & $2.3036(10)$ & 2.2391(11) \\
\hline Cu1-S1 ${ }^{i}$ & $2.2935(10)$ & $2.2540(11)$ \\
\hline Cu1-S1ii & $2.2413(10)$ & $2.2739(10)$ \\
\hline S1-Cu1-S1 ${ }^{i}$ & 103.69(3) & 123.62(4) \\
\hline S1-Cu1-S1ii & 129.82(4) & 122.32(4) \\
\hline S1'-Cu1-S1 ${ }^{i i}$ & $126.36(5)$ & $113.94(4)$ \\
\hline \multirow[t]{3}{*}{ Cu1 $\ldots$ Cu1 ${ }^{b)}$} & 2.997 & 3.305 \\
\hline & 3.512 & 3.485 \\
\hline & 3.897 & 3.960 \\
\hline
\end{tabular}

a) Symmetry codes: for compound 1: (i) $-x+1, y-1 / 2,-z+3 / 2$; (ii) $-x+1 / 2, y-1 / 2, z$; for compound 2: $110 \mathrm{~K}$ : (i) $x-1, y, z$; (ii) $x-1 / 2,-y+1, z+1 / 2$

b) Six nearest $\mathrm{Cu}$...Cu distances.

Overall, the lamellar structures of $\mathbf{1}$ and $\mathbf{2}$ are rather unusual since with the exception of the already mentioned $[\mathrm{CuHT}]_{n}$, the only single crystals so far reported are a series of $[\mathrm{Cu}(p$ $\left.\left.\mathrm{SC}_{6} \mathrm{H}_{4}-\mathrm{X}\right)\right]_{n}\left(\mathrm{X}=\mathrm{CH}_{3}, \mathrm{H}, \mathrm{CH}_{3} \mathrm{O}, \mathrm{NO}_{2}\right)$ [7] showing extended ladder-like [Cu-S] chains. In fact, the hexagonal bidimensional networks found in 1 and 2 based on $\mathrm{Cu}_{3} \mathrm{~S}_{3}$ fused rings structurally resemble to a single layer of $\beta$-phase antimony.[16] The crystal structures of 1 and 2 were also measured at 110 and $296 \mathrm{~K}$ in order to get some insight on the modification of the structural parameters, but only subtle changes were observed on the $\mathrm{Cu}$ S bond distances $(\leq 0.01 \AA)$, S-Cu-S angles $\left(\leq 0.3^{\circ}\right)$, and Cu $\cdots$ Cu distances $(\leq 0.01 \AA)$.

The thermal stability of $\mathbf{1}$ and $\mathbf{2}$ was studied by thermogravimetric analysis (TGA) and differential scanning calorimetry (DSC). Both showed thermal stabilities higher than $300{ }^{\circ} \mathrm{C}$ (Figures S5 and S6, Supporting Information).

\section{Morphological Studies}

Field-emission scanning electron microscopy (FESEM) analysis of polycrystalline 1 revealed the formation of well-defined plate-like crystals with hexagonal habit and average lateral dimensions of $13 \pm 6 \mu \mathrm{m}$ (Figure $3 \mathrm{a}, \mathrm{b}$ ). The side-view image of some of these crystals showed that their thickness range from $100 \mathrm{~nm}$ to nearly $1 \mu \mathrm{m}$ (Figure $2 \mathrm{~b}$, inset). In addition, as depicted in Figure S7 (Supporting Information), a higher magnification view confirmed the appearance of terraces on the crystal surface. 

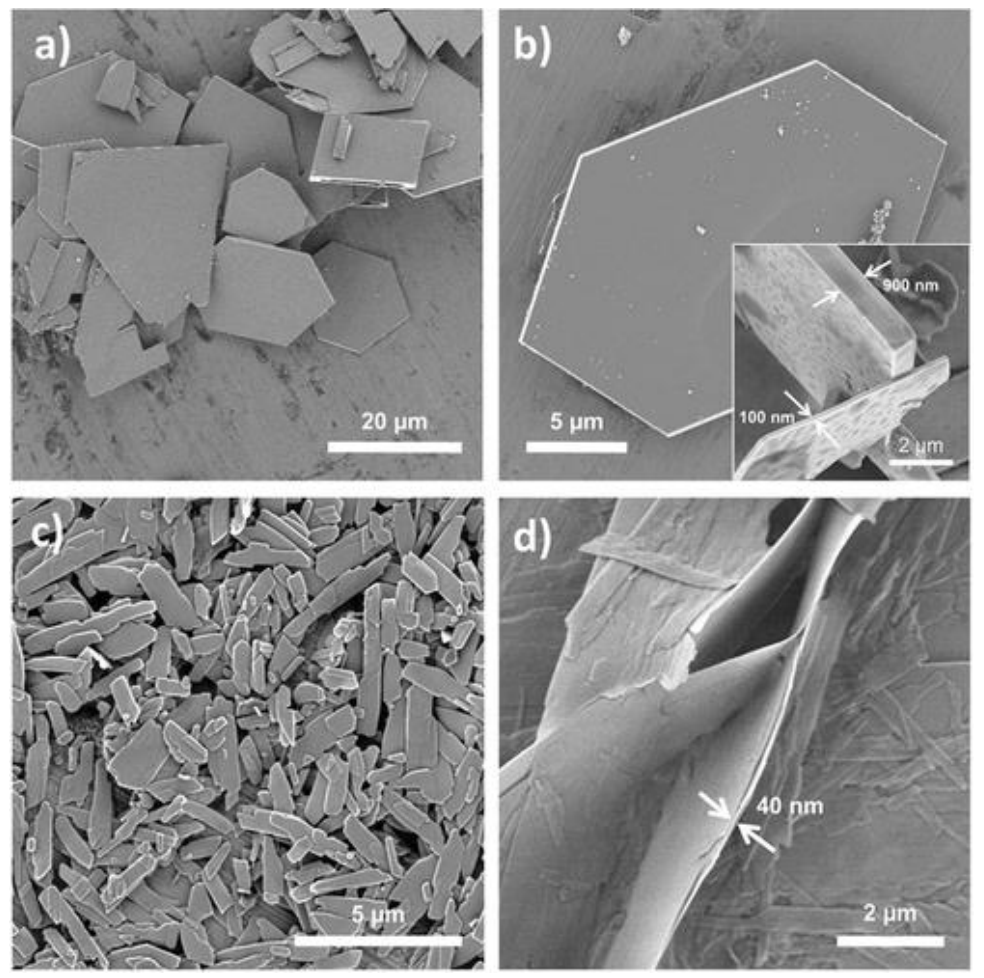

Figure 3. FESEM morphological analysis for $\mathbf{1}$ and $\mathbf{2}$. a) Low-magnification image of $\mathbf{1}$ microcrystals. b) View of an individual sheet of 1 and (inset) edge view of vertically oriented crystals. c) Lowmagnification image of elongated plate-like crystals of 2 . d) Edge view of vertically oriented and folded 2 nanosheets, showing their flexibility.

As in 1, FESEM images recorded for the polycrystalline form of 2 revealed the formation of aggregates of bidimensional crystals with lateral dimensions of $1-2 \mu \mathrm{m}$ in width and 1-10 $\mu \mathrm{m}$ in length (Figure 2c). Side view of some of these crystals showed that their thickness is $40 \pm 15 \mathrm{~nm}$ and that they could be folded meaning that they exhibit some flexibility (Figure 2d). In a similar manner, and as reported previously,[7] morphological characterization of $[\mathrm{CuHT}]_{n}$ confirmed that it crystallizes as aggregated platy crystallites whose lateral dimensions are several micrometers in length with nanometer thickness (Figure S8, Supporting Information). Overall, since these CPs grow as 2D plate-like crystals, it is feasible to imagine a strong correlation between the macroscopic laminar shape of the crystals and their 2D crystal structures.

\section{Switchable Luminescence Properties}

Copper(I) complexes with thiolate ligands are well-known to present luminescence.[3, 17] Thus far, however, most of the investigations have focused on polynuclear compounds or clusters, formed by 2 to $6 \mathrm{Cu}$ atoms, often with phosphines as coligands. [3,18] To this end, we evaluated the solid-state luminescence of the polymeric copper(I) thiolates 1, 2 and the previously described analogous [CuHT $]_{n .[7]}$

In the case of $[\mathrm{CuHT}]_{n}$, no emission upon UV excitation could be observed by naked eyes even under liquid nitrogen cooling. Emission spectrum of [CuHT] $]_{n}$ at room temperature was very close to that of the corresponding free ligand, 4-mercaptophenol (4-mp), as shown in Figure S9 (Supporting Information). These emissions could be assigned to ligand centered charge transfer transitions of the thiophenolate ligand $\left(\pi \rightarrow \pi^{*}\right)$.

Interestingly, inspection under UV-lamp of solid samples of $\mathbf{1}$ and $\mathbf{2}$ cooled to liquid nitrogen revealed a change in the color emission of $\mathbf{1}$, from pale yellow to green to orange, and a 
significant change in the color emission of 2 , from pale orange to green, which was easily distinguished by the naked eye (Figures $4 \mathrm{a}$ and $5 \mathrm{a}$ ). This thermochromism was reversible in both cases. To further investigate this thermochromic phenomenon, the temperaturedependent emissions of 1 and $\mathbf{2}$ together with the 4-mba and 4-mercaptometoxibenzoate (4$\mathrm{mmb}$ ) free ligands were measured to track their response to temperature.
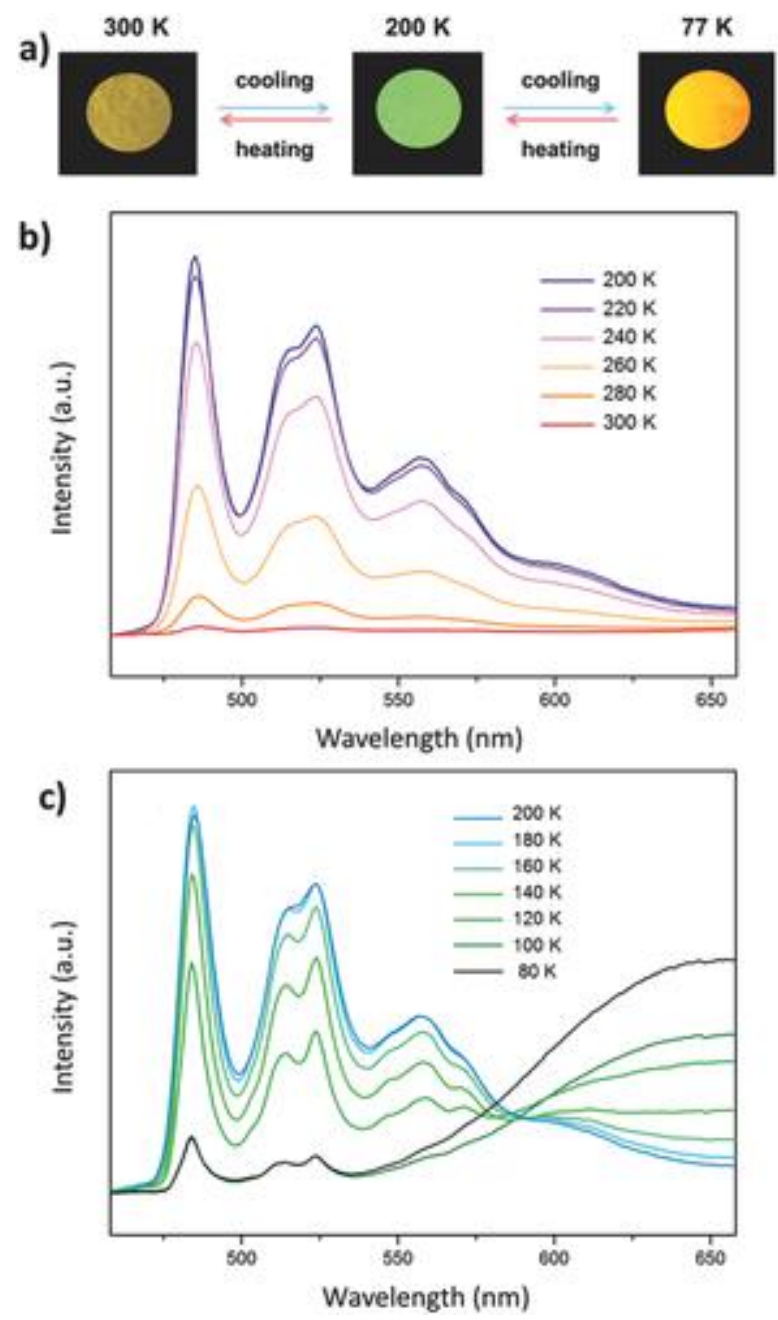

Figure 4. a) Representation showing the thermochromic behavior of 1 in the solid state under UV lamp excitation $\left(\lambda_{\text {exc }}=365 \mathrm{~nm}\right)$ at different temperatures. b) Temperature-dependent luminescence spectra of 1 in the solid state from $300 \mathrm{~K}$ down to $200 \mathrm{~K}\left(\lambda_{\text {exc }}=350 \mathrm{~nm} ; \Delta T=20 \mathrm{~K}\right)$. c) Temperaturedependent luminescence spectra of 1 in the solid state to $200 \mathrm{~K}$ down to $80 \mathrm{~K}\left(\lambda_{\mathrm{exc}}=350 \mathrm{~nm} ; \Delta T=20\right.$ $\mathrm{K})$. 


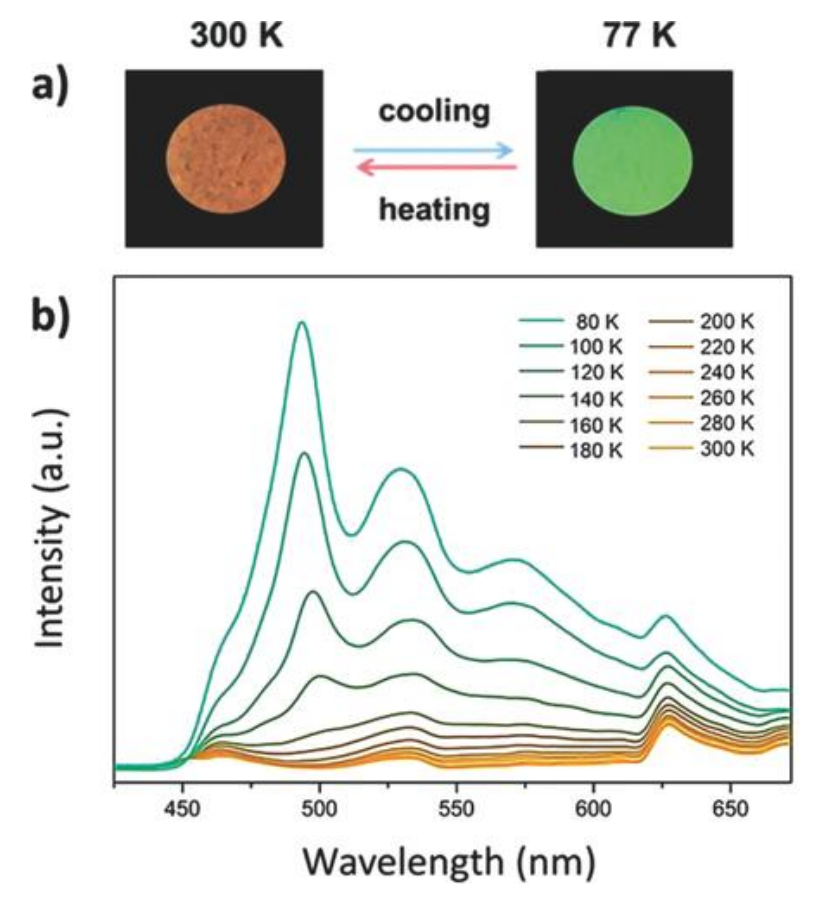

Figure 5. a) Representation showing the thermochromic behavior of 2 in the solid state under UV lamp excitation ( $\lambda_{\mathrm{exc}}=365 \mathrm{~nm}$ ) at room temperature (left) and under liquid nitrogen (right). b) Temperature-dependent luminescence spectra of 2 from $300 \mathrm{~K}$ down to $80 \mathrm{~K}$ in the solid state $\left(\lambda_{\mathrm{exc}}=\right.$ $350 \mathrm{~nm} ; \Delta T=20 \mathrm{~K})$.

The emission spectrum of 1 upon excitation at $350 \mathrm{~nm}$ at room temperature (Figure S10, Supporting Information) showed two strong bands, one narrow at $485 \mathrm{~nm}$ and a wide one at $523 \mathrm{~nm}$. Additionally, weak bands at lower energies at 557 and 573 (sh) nm were observed. Upon cooling, the intensity of these bands increased (Figure 3b), reaching the higher intensity at $200 \mathrm{~K}$ where structured bands at $485 \mathrm{~nm}$ and broader, better-resolved bands at 514 (sh), 523, 557, and 573 (sh) nm were observed. From 200 to $80 \mathrm{~K}$, the intensity of both bands slightly decreased, and a broadband centered at $\approx 650 \mathrm{~nm}$ was observed at $80 \mathrm{~K}$ (Figure 3c). The emission lifetimes were $0.34 \mathrm{~ms}$ at $280 \mathrm{~K}$ and $24 \mathrm{~ms}$ at $80 \mathrm{~K}$ for the highenergy band, and $1 \mathrm{~ms}$ for the low-energy band at $80 \mathrm{~K}$.

The emission spectrum of 2 at room temperature (Figure S11, Supporting Information) displayed similar bands to that showed in 1, bands at 451 (sh), 465, and $529 \mathrm{~nm}$, together with weak bands at 557 (sh) and $573 \mathrm{~nm}$ were observed. In addition, a very broadband at lower energy ( $629 \mathrm{~nm}$ ) was registered. The emission spectrum of 2 revealed, upon cooling, a pattern very similar to 1 (Figure $4 \mathrm{~b}$ ). Thus, the intensity of the bands increases rapidly reaching the higher intensity at $80 \mathrm{~K}$, where structured bands at 494, 530, and $570 \mathrm{~nm}$ were observed together with a broadband at $626 \mathrm{~nm}$. Remarkably, the high-energy emission band at 465 was red-shifted to $494 \mathrm{~nm}$ at $80 \mathrm{~K}\left(\Delta \lambda_{\max }=29 \mathrm{~nm}\right)$. The emission lifetimes for the high-energy band were of $728 \mu \mathrm{s}$ at $300 \mathrm{~K}$ and $32.8 \mathrm{~ms}$ at $80 \mathrm{~K}$.

We then compared the emission spectra of 1 and 2 with those of the free ligands, 4-mba and 4-mmb, at variable temperature (Figures $\mathrm{S} 12$ and S13, Supporting Information). Upon cooling, 1 and 2 displayed similar vibronic structures to that found for $4-\mathrm{mba}$ and $4-\mathrm{mmb}$. At room temperature, 1 exhibited a vibronic structure (Figure S10, Supporting Information). However, for 4-mba free ligand, a broad spectrum deprived of vibronic bands was observed (Figure S12, Supporting Information). In case of 2 and $4-\mathrm{mmb}$, at room temperature, the same vibronic structures were observed (Figures S11 and S13, Supporting Information). In both coordination polymers, the $\pi$-system of the benzene ring is only slightly perturbed when 
the coordination to copper take place, and a vibronic structure is observed. The difference between emission spectra of 1 and $4-\mathrm{mba}$ can be explained in terms of possible conformational changes of the carboxylic group $(\square \mathrm{COOH})$ when it is incorporated in the coordination polymer.[20]

The long excited-state lifetime observed for $\mathbf{1}$ and $\mathbf{2}$ suggested that the emission is most likely associated with a spin-forbidden transition of triplet parentage, and that a ligand--metal charge transfer ${ }^{3} \mathrm{LMCT}\left(\mathrm{S}^{2-} \rightarrow \mathrm{Cu}\right)$ excited state governs the spectra. The lifetime observed for the high-energy band for 1 enhanced from $0.34 \mathrm{~ms}$ at $280 \mathrm{~K}$ to $24 \mathrm{~ms}$ at $80 \mathrm{~K}$. In the case of 2 , the lifetime observed for the similar band increased from $728 \mu \mathrm{s}$ at $300 \mathrm{~K} \mu \mathrm{s}$ to $32.8 \mathrm{~ms}$ at $80 \mathrm{~K}$. These observations are consistent with a lower dissipative energy upon cooling, probably due to an increase of the medium rigidity. The weak bands centered at $\approx 650$ and $626 \mathrm{~nm}$ at $80 \mathrm{~K}$ for 1 and 2 , respectively, could be tentatively assigned to a mixed ${ }^{3}$ LMCT/MC state.[18]

In order to get a deeper insight into the reversible thermochromic behavior exhibited by 1 and 2, single-crystal X-ray analyses were performed for both CPs at $110 \mathrm{~K}$. These experiments showed, however, that no phase transition occurs upon cooling. The detailed crystal data, and selected bond lengths and bond angles of 1 and 2 at 110 and $296 \mathrm{~K}$ are collected in Tables S3 and S4 (Supporting Information). Although there are no significant changes in bond lengths and angles, we found a slight shrinkage of unit-cell size from $1331.27 \AA^{3}(296 \mathrm{~K})$ to $1327.6 \AA^{3}(110 \mathrm{~K})$ for 1 and from $396.70 \AA^{3}(296 \mathrm{~K})$ to $395.68 \AA^{3}(110$ $\mathrm{K})$ for 2 . At $110 \mathrm{~K}$, the lattice parameters $b$ and $c$ in $\mathbf{1}$ were shortened while the lattice parameter $a$ was elongated. For $\mathbf{2}$, the lattice parameters $a$ and $c$ were shortened and the lattice parameter $b$ was elongated. In this latter $\mathrm{CP}$, a shortening of the $\mathrm{CH}_{3} \cdots \mathrm{O}$ contact distances $(\approx 0.02 \AA)$ was observed at $110 \mathrm{~K}$.

The thermochromic behavior of 2 at 296 and $110 \mathrm{~K}$, associated to the reduction of the unitcell size, was also captured by the first-principles density functional theory (DFT)-based calculations of their many-body excitation spectra (see the Supporting Information). For that purpose, we computed the oscillator strengths of the major transitions contributing to the excitation spectra at that wavelength range, resulting those corresponding to $\mathrm{VB}$ $1 \rightarrow \mathrm{CB} / \mathrm{CB}+1$ transitions. The most important transitions corresponded to $\mathrm{VB}-1 \rightarrow \mathrm{CB}+1(\mathrm{HE})$ and to VB-1 $\rightarrow$ CB (LE), with oscillator strength values of 0.1565 at $486.5 \mathrm{~nm}$ and 0.0838 a.u. at $571.1 \mathrm{~nm}$ for $2_{296 \mathrm{~K}}$ (to be compared with the experimental values of 465 and $573 \mathrm{~nm}$, respectively), and 0.0604 at $503 \mathrm{~nm}$ and 0.2159 a.u. at $570 \mathrm{~nm}$ for $2_{110 \mathrm{~K}}$ (to be compared to the experimental values of 496 and $575 \mathrm{~nm}$, respectively). Interestingly, although this temperature-dependent structural change is not much significant, it has its reflection in a slight shift of around $16 \mathrm{~nm}$ of the HE band toward lower energies (to be compared with the experimental value of $29 \mathrm{~nm}$ ). This shift may be explained as a direct consequence of the reduction observed in electronic gap from 2.3 to $2.1 \mathrm{eV}$ passing from $\mathrm{RT}$ to $110 \mathrm{~K}$ conditions (Figure S14, Supporting Information). As expected, the band gaps obtained for 2 at RT and $110 \mathrm{~K}$ correlate well with the excitation threshold and the beginning of the photoabsorption (Figure S15, Supporting Information), which starts at around 0.6 and $0.8 \mathrm{eV}$ for $2296 \mathrm{~K}$ (gap: $2.1 \mathrm{eV}$ ) and $2_{110 \mathrm{~K}}$ (gap: $2.3 \mathrm{eV}$ ), respectively. It is also interesting to notice an increment in the oscillator strength in the HE band from RT to $110 \mathrm{~K}$, as evidenced by the experimental data. From the calculations, no additional information could be extracted for the LE band, which remains located at the same energy with a weaker intensity for $\mathbf{2}_{110 \mathrm{~K}}$.

An analogous study was repeated for the crystal structures of 1 determined at RT and $110 \mathrm{~K}$ $\left(\mathbf{1}_{296} \mathrm{k}\right.$ and $\left.\mathbf{1}_{110 \mathrm{~K}}\right)$. For both structures, the major transitions contributing to the excitation spectra at that wavelength range were those corresponding to the VB-1/VB $\rightarrow$ CB transitions. 
In particular, the most important transitions in $\mathbf{1}_{110 \mathrm{k}}$ were the VB-1 $\rightarrow \mathrm{CB}$ and $\mathrm{VB} \rightarrow \mathrm{CB}$, with oscillator strength values of 0.2263 a.u. at $453 \mathrm{~nm}$ and 0.1898 a.u. at $543 \mathrm{~nm}$. Similarly, the most important transitions in $\mathbf{1}_{296} \mathrm{k}$ were again the VB-1 $\rightarrow$ CB and $\mathrm{VB} \rightarrow \mathrm{CB}$, with oscillator strength values of 0.1765 a.u. at $459 \mathrm{~nm}$ and 0.1321 a.u. at $552 \mathrm{~nm}$. Both computed major transitions observed for 1 at RT and $110 \mathrm{~K}$ seem to correspond to the structured band experimentally detected between 485 and $557 \mathrm{~nm}$ from $80 \mathrm{~K}$ up to around $200 \mathrm{~K}$. However, for higher temperatures, a broadband at around $620 \mathrm{~nm}$ emerged in the experiment that our theoretical approximation was not able to capture, which may be associated to purely thermal effects inducing an electronic states broadening. Nevertheless, it is interesting to notice how the mentioned computed oscillator strengths substantially decreased from $\mathbf{1}_{110}$ kto $1_{296} \mathrm{k}$, which is also noticeable in the experiment where the structured band vanishes at RT. Furthermore, similar to 2 , the computed band gaps obtained for 1 at RT and $110 \mathrm{~K}$ (Figure S14, Supporting Information) also correlate with the excitation threshold and with the beginning of the computed photoabsorption spectra (Figure S15b, Supporting Information), which starts at around 0.9 and $1.1 \mathrm{eV}$ for $\mathbf{1}_{296 \mathrm{~K}}$ (gap: $2.4 \mathrm{eV}$ ) and $\mathbf{2}_{110 \mathrm{~K}}$ (gap: $2.3 \mathrm{eV}$ ). It is interesting to notice that low-temperature structures exhibit lower band gaps (Figure S14, Supporting Information) and lower excitation thresholds (Figure S15, Supporting Information), and that these excitation thresholds are lower for $\mathbf{2}$ than $\mathbf{1}$, thereby yielding lower gaps for both low and high-temperature structures in $\mathbf{2}$.

Additionally, given that the most important computed electronic transitions correspond to the VB, the CV, and states close to them, we have computed the valence and conduction band orbital electron 3D isodensities for the different compounds studied (Figure S16, Supporting Information) in order to check their spatial morphology. In this figure, it is possible to observe that the valence band for all the compounds is mostly located in the metallic chains with some minor contribution within the aromatic rings of the ligands, while the conduction band shows a substantial depletion in the metallic chain being mostly located in the ligands.

Overall, comparison of the optical properties of $\mathbf{1}$ and $\mathbf{2}$ clearly indicated that the presence of substituents with different electronic properties in the para position of the phenyl ring has a clear influence in their emission spectra. This could be explained in accordance with the significant modifications observed in some of the structural parameters of the $\mathrm{Cu}_{3} \mathrm{~S}_{3}$ rings conformation (half-chair for 1 vs twist-boat for 2), the thickness of the inorganic core of the 2D sheet ( 2.037 for 1 vs $2.163 \AA$ for 2 ), the dihedral angle between the phenyl rings inside the sheet (parallel for 1 vs $50^{\circ}$ for 2 ), and the supramolecular interactions that held together the layers (hydrogen bonding for $\mathbf{1}$ vs weak van der Waals interactions for $\mathbf{2}$ ).

\section{Composites Films}

Recently, it has been suggested that nanoscale plate-like crystals of porous MOFs can be integrated into polymers in a more homogeneous way, allowing the fabrication of mixed matrix membranes with effective separation properties.[21] Following this idea, we considered that the plate-like crystals of $\mathbf{1}$ and $\mathbf{2}$ could also be used for the fabrication of homogeneous thin films that exhibit reversible thermochromic responses.

Figure 6a shows a schematic illustration of the process followed to fabricate these composite thin films. The preparation started with the dispersion of crystals of $\mathbf{1}$ or $\mathbf{2}$ in a DMF solution of polyvinylidene difluoride (PVDF). This homogenous suspension was drop-casted on a glass substrate and dried at $85^{\circ} \mathrm{C}$. After solvent removal, a homogeneous film was formed and detached from the substrate upon immersion in water. Figure $5 b$ shows the resulting 1@PVDF and 2@PVDF thin films with a CP content of 50\% (wt \%). Notably, they were completely freestanding, free of macroscopic defects and robust under mechanical bending stress (Figure 5c). The cross-section FESEM images of 1@PVDF and 2@PVDF 
revealed a film thickness of 75 and $35 \mu \mathrm{m}$, respectively (Figure $5 \mathrm{~d}$ ). This difference between both films could tentatively be explained by the smaller thickness and higher flexibility of crystals of 2 , allowing better packing during the evaporation process and resulting in a higher densification of the composite film.

a)

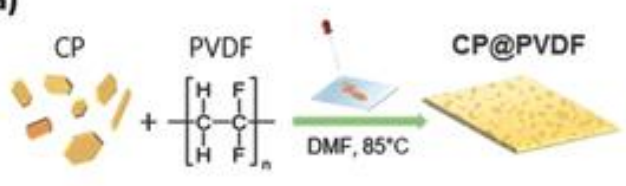

c)

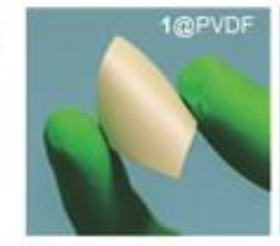

e)

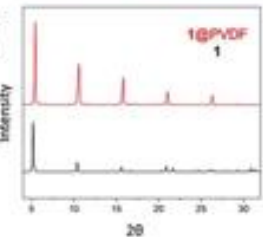

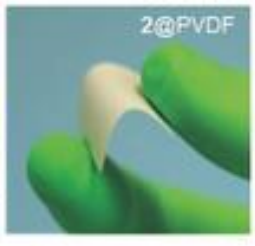

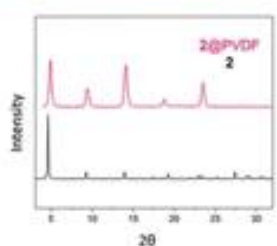

b)

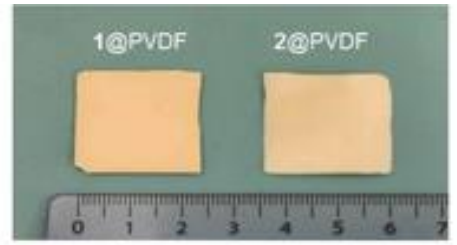

d)

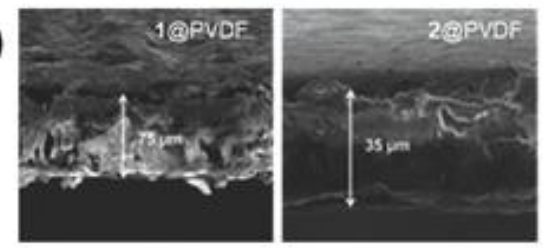

f)

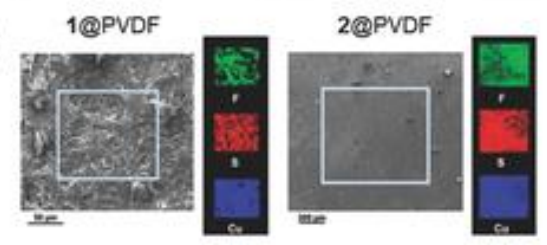

Figure 6. a) Schematic diagram of the fabrication of CP@PVDF composites via drop casting. b) Picture of as-prepared 1@PVDF and 2@PVDF thin films with $50 \%$ (wt\%) of $\mathbf{1}$ and 2, respectively. c) Pictures of 1@PVDF and 2@PVDF thin films showing their flexibility. d) Cross-section FESEM images of 1@PVDF and2@PVDF thin films. e) XRPD patterns of 1@PVDF (left) and 2@PVDF (right) compared to the corresponding polycrystalline solids. f) SEM-EDS elemental mapping images of the outward facing surfaces of 1@PVDF (left) and 2@PVDF (right), showing the homogeneous distribution of fluorine (green), sulfur (red), and copper (blue).

The XRPD patterns confirmed that the crystallinity of both CPs was retained after the fabrication process (Figure 5e). Energy-dispersive X-ray spectrum (EDS) revealed that crystals of $\mathbf{1}$ and $\mathbf{2}$ are homogeneously distributed along the plane of the fabricated thin films (Figure 5f). However, detailed analysis of FESEM images showed a different distribution of CP crystals between the two sides of the films (Figure S17, Supporting Information). In them, the side against the glass substrate presented a higher PVDF content, whereas the other side was richer in crystals. This effect was already observed in the preparation of MOFbased mixed matrix membranes by drop casting.[21]

To evaluate that the fabricated 1@PVDF and 2@PVDF films retained the thermochromic properties of $\mathbf{1}$ and $\mathbf{2}$, we examined them under UV irradiation (Figure 7). Remarkably, 1@PVDF exhibited thermochromism upon cooling down from 300 to $77 \mathrm{~K}$, changing its color from to pale yellow (room temperature) to green (200 K) to orange $(77 \mathrm{~K})$ (Figure 6a). This thermochromic behavior was fully reversible upon warming, as illustrated in Figure 6b. Similarly, 2@PVDF also exhibited a marked reversible chromic response upon changing the temperature, switching from pale orange (room temperature) to green $(77 \mathrm{~K})$ (Figure $6 \mathrm{c}$ ). The emission spectra of both films were registered at variable temperature. Both show similar thermochromic behavior than 1 and 2 (Figure S18, Supporting Information). 


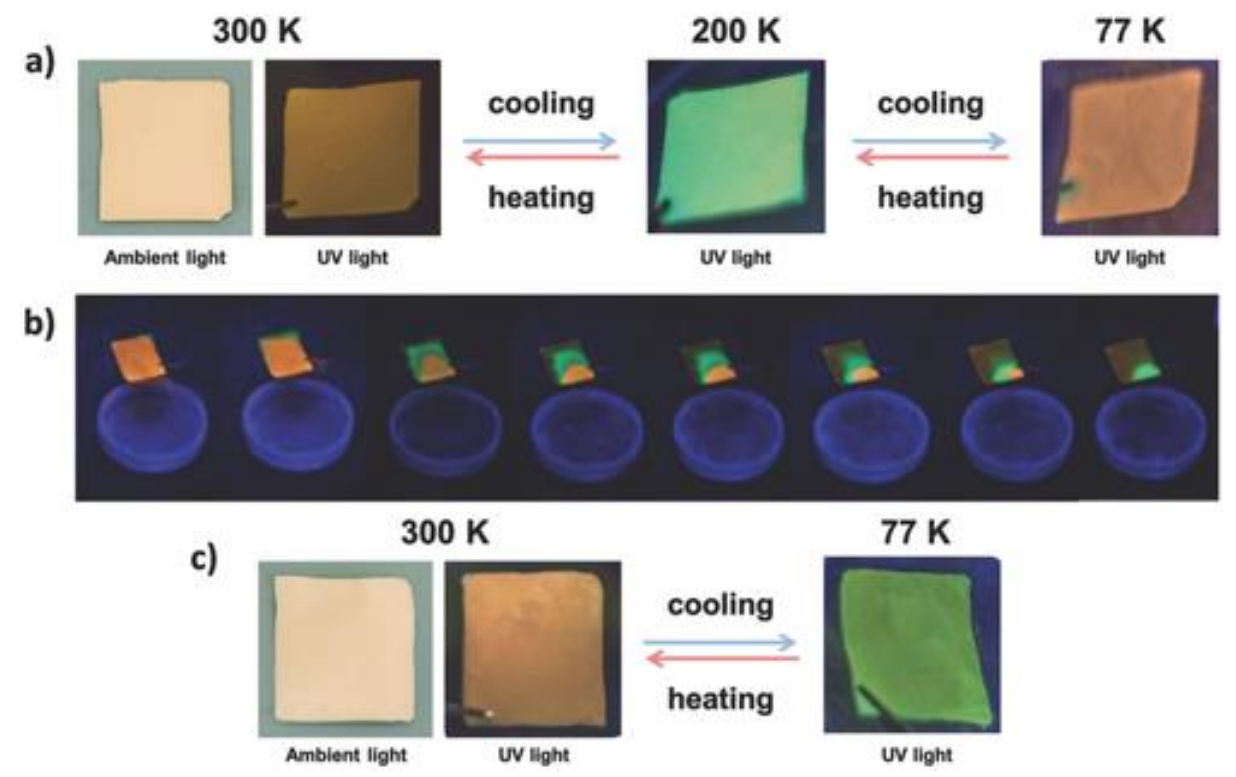

Figure 7. Illustration of the thermochromic behavior of 1@PVDF and 2@PVDF thin films. a) Solidstate emission of $1 @ P V D F$ under ambient light and UV lamp excitation $\left(\lambda_{\text {exc }}=365 \mathrm{~nm}\right)$ at different temperatures. b) Sequential pictures of 1@PVDF film during warming from $77 \mathrm{~K}$ to room temperature under UV lamp excitation $\left(\lambda_{\mathrm{exc}}=365 \mathrm{~nm}\right)$. c) Solid-state emission of 2@PVDF under ambient light and UV lamp excitation $\left(\lambda_{\mathrm{exc}}=365 \mathrm{~nm}\right)$ at different temperatures.

We have also analyzed the effect of reducing the amount of CP crystals on the optical properties of the composite films. To this end, we prepared 1@PVDF thin films with a CP content ranging from 50 to $9 \mathrm{wt} \%$ by following the same methodology. Characterization of the lower content composite film 1@PVDF (9 wt\%) is shown in Figure S19 (Supporting Information). These films showed a thermochromic luminescent response similar to $1 @$ PVDF (50 wt\%), although the emission intensity decreases as the CP content diminishes. Besides, the transparency of the films increases with decreasing of the CP content as shown in Figure S20a (Supporting Information). Remarkably, the generated 1@PVDF film with a 9 wt\% displayed a reasonable transparency (40-80\%) in the visible range (Figure S20b, Supporting Information). In addition, it shows a satisfactory thermochromic luminescent response (Figure S19d, Supporting Information).

Finally, we have evaluated the mechanical properties of the composite films by submitting the 1@PVDF and 2@PVDF films with a CP content of 9 and 50 wt\% to tensile test (Figure S21, Supporting Information). Mechanical behavior is summarized in Figure S22 (Supporting Information).1@PVDF and 2@PVDF at 9 wt\% films show an almost negligible change in ultimate tensile strength and elastic modulus to that observed for naked PVDF (Figures S23 and S24, Supporting Information), whereas both strength and modulus are significantly reduced for the films at $50 \mathrm{wt} \%$. Additionally, Figure S25 (Supporting Information) shows that an increase of the amount of CPs in the composite films produces a decrease in the material ductility. However, the flexibility of the composite films is still remarkable.

\section{Conclusions}

Two new CPs based on $\mathrm{Cu}(\mathrm{I})$ and thiophenolate ligands with general formula $[\mathrm{Cu}(p$ $\mathrm{SPhCOO}-\mathrm{X})]_{n}(\mathrm{X}=\mathrm{H}, \mathbf{1}$ and $\mathrm{Me}, 2)$ have been synthesized by direct one-pot reaction between $\mathrm{Cu}\left(\mathrm{BF}_{4}\right)_{2} \cdot \mathrm{xH}_{2} \mathrm{O}$ and 4 -mba using different solvents. The so-formed materials consist of $2 \mathrm{D}$ crystals of sub-micro- (for $\mathbf{1}$ ) and nanometric (for 2 ) thicknesses, and large lateral dimensions, in the micrometer range. X-ray diffraction studies on single crystals confirm that 1 and 2 display rather similar layered structures. 1 and $\mathbf{2}$ show reversible thermochromic 
luminescence, with changes from pale yellow to green to orange and from pale orange to green for 1 and 2, respectively, upon cooling down to $77 \mathrm{~K}$. Variable temperature experiments indicate that there is direct evidence that luminescent thermochromism of these compounds is caused by a higher rigidity and even a more efficient packing of the ligands, according to the decrease in volume of the unit cell observed at $110 \mathrm{~K}$.

Interestingly, the simple processability of $\mathbf{1}$ and $\mathbf{2}$ as plate-like crystals and their high dispersibility in DMF enable their integration with PVDF to form homogeneous thin film composites retaining the reversible thermochromic response of these $\mathrm{CPs}$ and the mechanical properties of the PVDF matrix. Importantly, the transparency of the composite films can be tuned with the quantity of CP nanosheets while their mechanical behavior is only significantly affected upon high $\mathrm{CP}$ content, as previously reported for similar MOF composite films.[21]

This simple fabrication procedure enables practical application as thermal stimuli-responsive thin films potentially useful for electronic and optoelectronic devices, including light-emitting diodes, solar cells, photodetectors, flat-panel displays, and chemical and biological sensors.[1]

\section{Experimental Section}

\section{Materials and Methods}

All the reagents were purchased from Sigma-Aldrich and used as received. FTIR spectra (KBr pellets) were recorded on a Perkin-Elmer 1650 spectrophotometer. C, H, N, S elemental analyses were performed by the Microanalysis Service of the Universidad Autónoma de Madrid on a Perkin-Elmer 240 B microanalyser. Powder X-ray diffraction experiments were carried out on a Diffractometer PANalytical X'Pert PRO $\theta / 2 \theta$ primary monochromator and detector with fast X'Celerator. The samples were analyzed with scanning $\theta / 2 \theta$. FESEM images were collected on a FEI Magellan 400L scanning electron microscope at an acceleration voltage of $2.0 \mathrm{kV}$ and FEI Quanta 650F scanning electron microscope with EDX Inca 250 SSD XMax20 at an acceleration voltage of $20.0 \mathrm{kV}$, using aluminum as support. Steady-state photoluminescence spectra were recorded on a JobinYvon Horiba Fluorolog FL-3-11 spectrometer using band pathways of $3 \mathrm{~nm}$ for both excitation and emission. Phosphorescence lifetimes were recorded with an IBH 5000F coaxial nanosecond flashlamp. The lifetime data were fitted with the Jobin-Yvon software package. Measurements at variable temperature were done with an Oxford Cryostat Optistat DN. The lifetime data were fitted using the Jobin-Yvon IBH software DAS6 v6.1.

\section{Theoretical Methodology}

All the DFT-based calculations were carried out by the accurate and efficient plane-wave code QUANTUM ESPRESSO.22 Within this atomistic simulation package, the Kohn-Sham equations were solved using a periodic supercell geometry. The exchange-correlation (XC) effects were accounted through the generalized gradient approximation (GGA) within the Perdew-Burke-Ernzerhof (PBE) parameterization.23 To model the ion-electron interaction in the $\mathrm{H}, \mathrm{C}, \mathrm{O}, \mathrm{S}$, and $\mathrm{Cu}$ atoms, Rabe Rappe Kaxiras Joannopoulos (RRKJ) ultrasoft

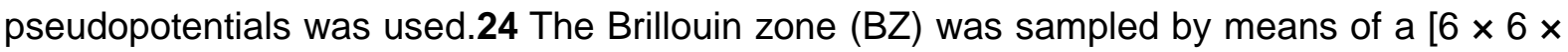
1] Monkhorst-Pack grid25 (where the Cartesian $X Y$ plane corresponds here to the laminar plane) for $\mathbf{1}$ and $\mathbf{2}$. The one-electron wave-functions were expanded in a basis of planewaves with energy cutoffs of 400 and $500 \mathrm{eV}$ for the kinetic energy and for the electronic density, respectively, which were adjusted to achieve sufficient accuracy to guarantee a full convergence in energy and density. For the computation of the many-body excitation 
spectra, the aforementioned standard DFT formalism was used combined with many-body perturbation theory via the quasi-particle approximation GW correction 26 to conventional DFT, combined with the Bethe-Salpeter equation (BSE)27 for the calculation of the excitation spectrum implemented within the YAMBO code.28 The BSE was solved for coupled electron-hole excitations, thereby accounting for the screened electron-hole attraction and the unscreened electron-hole exchange.

\section{X-Ray Data Collection and Crystal Structure Determination}

The X-ray diffraction data collections and structure determinations were done on a Bruker Kappa Apex II diffractometer using graphite-monochromated Mo-Ka radiation $(\lambda=0.71073$ $\AA)$. The cell parameters were determined and refined by a least-squares fit of all reflections. A semi-empirical absorption correction (SADABS) was applied for all cases. All the structures were solved by direct methods using the SIR92 program29 and refined by fullmatrix least-squares on $\mathrm{F}^{2}$ including all reflections (SHELXL97).30 All calculations were performed using the WINGX crystallographic software package.31 All nonhydrogen atoms were refined anisotropically. The hydrogen atoms were included in their calculated positions and refined riding on the respective parent atoms. Relevant data acquisition and refinement parameters are gathered in Tables S1 and S2 (Supporting Information).

\section{Mechanical Testing}

The mechanical test of the samples were carry out in an Universal Testing Machine IBTH 500 (SAE Ibertest) equipped with a $500 \mathrm{~N}$ load cell. The measurements of load and displacement were acquired using a crosshead speed of $0.5 \mathrm{~mm} \mathrm{~min}^{-1}$ and the stress-strain curves for each specimen were obtained. Three different measurements were carried out for each composite sample. The values shown in Table S5 and Figures S23-S25 (Supporting Information) correspond to an average of three measurements for each sample and the bars indicate the standard deviation. Specimens for tensile testing were prepared with composite films of $100 \mathrm{~mm}$ long, $25 \mathrm{~mm}$ wide, and $0.1 \mathrm{~mm}$ thick. In order to avoid the clamping jaws cause a damage in the samples, a VHB tape of $1 \mathrm{~mm}(3 \mathrm{M})$ was used (Figure S21, Supporting Information). The length between tapes was $30 \mathrm{~mm}$, as well as the initial separation between clamping jaws.

Synthesis of [CuCT]n (1): A mixture of $\mathrm{Cu}\left(\mathrm{BF}_{4}\right)_{2} \cdot \mathrm{xH}_{2} \mathrm{O}(0.118 \mathrm{~g}, 0.50 \mathrm{mmol})$ and 4mercaptobenzoic acid $(0.154 \mathrm{~g}, 1.00 \mathrm{mmol})$ in $20 \mathrm{~mL}$ of acetone was sealed in a $23 \mathrm{~mL}$ Teflon-lined stainless steel autoclave. The reactor was heated at $120^{\circ} \mathrm{C}$ for $48 \mathrm{~h}$ and then allowed to cool to room temperature. A pale yellow powder was obtained, washed with DMF and diethyl ether, and then dried in a vacuum line at $60^{\circ} \mathrm{C}$ for $4 \mathrm{~h}(0.085 \mathrm{~g}, 78 \%$ yield based on $\mathrm{Cu}$ ). Anal. calcd (\%) for $\mathrm{C}_{7} \mathrm{H}_{5} \mathrm{CuO}_{2} \mathrm{~S}$ : C, 38.79; $\mathrm{H}, 2.33 ; \mathrm{S}, 14.80$. Found (\%): C, 38.95; $\mathrm{H}$, 2.46; S, 14.48. IR (KBr, cm$\left.{ }^{-1}\right)$ : 2960 (w), 1682 (s), $1589(\mathrm{~m}), 1560$ (w), $1427(\mathrm{~m}), 1394(\mathrm{~m})$, $1290(\mathrm{~m}), 1279(\mathrm{~m}), 1128(\mathrm{w}), 1082(\mathrm{w}), 841$ (w), $760(\mathrm{~m})$. Colorless plate crystals of 1 suitable for single-crystal X-ray diffraction were obtained following the procedure abovementioned except that DMF $(4 \mathrm{~mL})$ was used as solvent and the reactor was cooled down to room temperature at a rate of $5^{\circ} \mathrm{C} \mathrm{h}^{-1}$.

Synthesis of [CUMCT] $(2): 2$ was synthesized by a method similar to that for 1, except that methanol $(20 \mathrm{~mL})$ was used as solvent. A yellow powder was obtained, washed with hot methanol, DMF, and diethyl ether, and then dried under vacuum at $60{ }^{\circ} \mathrm{C}$ for $4 \mathrm{~h}(0.085 \mathrm{~g}$, $74 \%$ yield based on $\mathrm{Cu}$ ). Anal. calcd (\%) for $\mathrm{C}_{8} \mathrm{H}_{7} \mathrm{CuO}_{2} \mathrm{~S}: \mathrm{C}, 41.64 ; \mathrm{H}, 3.06$; $\mathrm{S}, 13.89$. Found (\%): C, 41.67; H, 3.16; S, 13.78. IR (KBr, cm $\left.{ }^{-1}\right): 2950$ (w), 1720 (s), $1589(\mathrm{~m}), 1485(\mathrm{w})$, $1435(\mathrm{~m}), 1392(\mathrm{~m}), 1277(\mathrm{~s}), 1180(\mathrm{~m}), 1111(\mathrm{~s}), 1011(\mathrm{~m}), 825(\mathrm{w}), 752(\mathrm{~m}), 683(\mathrm{w})$. 
Bright yellow crystals of 2 suitable for single-crystal X-ray diffraction were obtained by mixing $\mathrm{Cu}\left(\mathrm{BF}_{4}\right)_{2} \cdot x \mathrm{H}_{2} \mathrm{O}(0.024 \mathrm{~g}, 0.10 \mathrm{mmol})$ with bis- $p$-methoxycarbonyl-phenyl disulfide $(0.034 \mathrm{~g}$, $0.10 \mathrm{mmol}$ ) in $4 \mathrm{~mL}$ of DMF. The reactor was heated at $140{ }^{\circ} \mathrm{C}$ for $20 \mathrm{~h}$ and then slowly cooled down to room temperature at a rate of $4{ }^{\circ} \mathrm{C} \mathrm{h}^{-1}$.

Synthesis of $\left(\mathrm{p}-\left(\mathrm{CO}_{2} \mathrm{Me}\right) \mathrm{PhS}\right)_{2}$ : Bis- $p$-methoxycarbonyl-phenyl disulfide was obtained as a subproduct during the synthesis of $\mathbf{2}$. In this synthesis, a white solid was obtained after the hot methanol washing solution was joined to the mother solution and the solvent was removed under reduced pressure. This solid was washed with diethyl ether and dried under vacuum $(0.101 \mathrm{~g}, 60 \%$ yield based on $4-\mathrm{mba})$. Recrystallization from diethyl ether afforded the product as white crystals suitable for X-ray analysis. ${ }^{1} \mathrm{H} N M R\left(300 \mathrm{MHz}, \mathrm{CD}_{3} \mathrm{OD}\right): \delta=$ $7.97(4 \mathrm{H}, \mathrm{m}), \delta=7.64(4 \mathrm{H}, \mathrm{s}), \delta=3.90(6 \mathrm{H}, \mathrm{s}) \mathrm{ppm}$. IR $\left(\mathrm{KBr}, \mathrm{cm}^{-1}\right): 2997(\mathrm{w}), 2947(\mathrm{w})$, $1716(\mathrm{~s}), 1589(\mathrm{~m}), 1485(\mathrm{w}), 1435(\mathrm{~m}), 1396(\mathrm{~m}), 1277(\mathrm{~s}), 1180(\mathrm{~m}), 1107(\mathrm{~s}), 1076(\mathrm{~m})$, $1011(\mathrm{~m}), 845(\mathrm{w}), 825(\mathrm{w}), 756(\mathrm{~m}), 686(\mathrm{w})$.

Synthesis of 4-Mercaptometoxibenzoate: 4-Mercaptobenzoic acid (0.308 g, $2.00 \mathrm{mmol})$ was dissolved in $50 \mathrm{~mL}$ of methanol and $1 \mathrm{~mL}$ of hydrochloric acid (37\%) was added. The mixture was refluxed overnight under stirring and then evaporated to dryness. The residue was washed with distilled water and recrystallized in diethyl ether $(0.302 \mathrm{~g}, 90 \%$ yield $) .{ }^{1} \mathrm{H}$ $\operatorname{NMR}\left(300 \mathrm{MHz},\left(\mathrm{CD}_{3}\right)_{2} \mathrm{SO}\right): \delta=7.95(2 \mathrm{H}, \mathrm{d}), \delta=7.66(2 \mathrm{H}, \mathrm{d}), \delta=3.83(3 \mathrm{H}, \mathrm{s}) \mathrm{ppm}$. IR $(\mathrm{KBr}$, $\mathrm{cm}^{-1}$ ): 2945 (w), $2574(\mathrm{~m}), 1705$ (s), 1589 (s), 1485 (w), 1431 (m), 1273 (s), 1177 (s), 1106 (s), $1007(\mathrm{~m}), 954(\mathrm{w}), 898(\mathrm{~m}), 834(\mathrm{~m}), 754(\mathrm{~s}), 689(\mathrm{~m})$.

Synthesis of [CuHT] $]_{n}$ : For this synthesis, an analogous method to that reported previously was used,[7] with a soluble metal precursor. Thus, a mixture of $\mathrm{Cu}\left(\mathrm{BF}_{4}\right)_{2} \cdot x \mathrm{H}_{2} \mathrm{O}(0.118 \mathrm{~g}$, $0.50 \mathrm{mmol})$ and 4-mercaptophenol $(0.127 \mathrm{~g}, 1.00 \mathrm{mmol})$ in $20 \mathrm{~mL}$ of ethanol was heated under reflux with stirring for $24 \mathrm{~h}$ under an argon atmosphere. The yellow precipitate was filtered off, washed with ethanol and diethyl ether, and then dried in a vacuum line at $60^{\circ} \mathrm{C}$ for $4 \mathrm{~h}(0.053 \mathrm{~g}, 56 \%$ yield based on $\mathrm{Cu})$. Anal. Calcd. (\%) for $\mathrm{C}_{6} \mathrm{H}_{5} \mathrm{CuOS}$ : C, 38.19; $\mathrm{H}, 2.67$; S, 16.99. Found (\%): C, 38.03; H, 2.64; S, 17.00. IR (KBr, cm $\left.{ }^{-1}\right): 3395$ (s),1651 (w), 1591 $(\mathrm{m}), 1489(\mathrm{~s}), 1432(\mathrm{~s}), 1360(\mathrm{~m}), 1253(\mathrm{~s}), 1097(\mathrm{w}), 1012(\mathrm{w}), 820(\mathrm{~m}), 802(\mathrm{~m}), 638(\mathrm{w})$, $511(\mathrm{~m})$.

Preparation of CP@PVDF Thin Films: CPs and PVDF were mixed in different proportions and were dispersed in DMF with sonication until total solution of the polymer. The resulting homogeneous suspension was casted on microscope slide and dried at $85{ }^{\circ} \mathrm{C}$ to remove the DMF. The resulting CP@PVDF films were delaminated via immersion in water and dried in air.

[CCDC 1504677-1504680 and 1520848 contain the supplementary crystallographic data for this paper. These data can be obtained free of charge from The Cambridge Crystallographic Data Centre via www.ccdc.cam.ac.uk/data request/cif.]

\section{Acknowledgements}

This work was supported by the Spanish MINECO (projects PN MAT2015-65354-C2-1-R, MAT2013-46753-C2-1-P, MAT2016-75883-C2-1-P, MAT2016-77608-C3-1-P, and CTQ2016-75816-C2-1-P), the Catalan AGAUR (project 2014 SGR 80), and the ERC under the EU FP7 (ERC-Co 615954). It was also funded by the CERCA Programme/Generalitat de Catalunya. ICN2 acknowledges the support of the Spanish MINECO through the Severo Ochoa Centers of Excellence Program, under Grant No. SEV-2013-0295. F.Z. thanks the "María de Maeztu" Programme for Units of Excellence in R\&D (MDM-2014-0377). The authors thank Dr. Vincent Guillerm for the photographic work. 


\section{Conflict of Interest}

The authors declare no conflict of interest.

\section{References}

1a) Xu, H., Chen, R., Sun, Q., Lai, W., Su, Q., Huang, W., Liu, X., Chem. Soc. Rev. 2014, 43, 3259; b) Wang, F., Raval, Y., Chen, H., Tzeng, T.-R. J., DesJardins, J. D., Anker, J. N., Adv. Healthcare Mater. 2014, 3, 197; c) Liu, J., Yao, Q., Li, Y., Appl. Phys. Lett. 2006, 88, 173119; d) Kwon, W., Do, S., Lee, J., Hwang, S., Kim, J. K., Rhee, S.-W., Chem. Mater. 2013, 25, 1893; e) Currie, M. J., Mapel, J. K., Heidel, T. D., Goffri, S., Baldo, M. A., Science 2008, 321, 226; f) Guan, W., Zhou, W., Lu, J., Lu, C., Chem. Soc. Rev. 2015, 44, 6981; g) Fujihara, S., Chemical Solution Deposition of Functional Oxide Thin Films, Springer, Vienna, Austria 2013; h) Miao, R., Peng, J., Fang, Y., Mol. Syst. Des. Eng. 2016, 1, 242; i) Lü, F., Gao, L., Ding, L., Jiang, L., Fang, Y., Langmuir 2006, 22, 841; j) Aparicio, F. J., Holgado, M., Borras, A., Blaszczyk-Lezak, I., Griol, A., Barrios, C. A., Casquel, R., Sanza, F. J., Sohlström, H., Antelius, M., González-Elipe, A. R., Barranco, A., Adv. Mater. 2011, 23, 761.

2a) Feng, J., Tian, K., Hu, D., Wang, S., Li, S., Zeng, Y., Li, Y., Yang, G., Angew. Chem., Int. Ed. 2011, 50, 8072; b) Brites, C. D. S., Lima, P. P., Silva, N. J. O., Millán, A., Amaral, V. S., Palacio, F., Carlos, L. D., Adv. Mater. 2010, 22, 4499; c) Guo, H., Zhang, J., Porter, D., Peng, H., Lowik, D. W. P. M., Wang, Y., Zhang, Z., Chen, X., Shao, Z., Chem. Sci. 2014, 5, 4189; d) Yan, D., Lu, J., Ma, J., Wei, M., Evans, D. G., Duan, X., Angew. Chem., Int. Ed. 2011, 50, 720; e) Brites, C. D. S., Lima, P. P., Silva, N. J. O., Millan, A., Amaral, V. S., Palacio, F., Carlos, L. D., Nanoscale 2012, 4, 4799; f) Rocha, J., Brites, C. D. S., Carlos, L. D., Chem. - Eur. J. 2016, 22, 14782; g) Wang, X.-D., Wolfbeis, O. S., Meier, R. J., Chem. Soc. Rev. 2013, 42, 7834.

3a) Osawa, M., Chem. Commun. 2014, 50, 1801; b) Perruchas, S., Goff, X. F., Maron, S., Maurin, I., Guillen, F., Garcia, A., Gacoin, T., Boilot, J.-P., J. Am. Chem. Soc. 2010, 132, 10967; c) Ford, P. C., Cariati, E., Bourassa, J., Chem. Rev. 1999, 99, 3625; d) Li, B., Huang, R.-W., Qin, J.-H., Zang, S.-Q., Gao, G.-G., Hou, H.-W., Mak, T. C. W., Chem. - Eur. J. 2014, 20, 12416; e) Zhuo, H.-Y., Su, H.-F., Cao, Z.-Z., Liu, W., Wang, S.-A., Feng, L., Zhuang, G.-L., Lin, S.-C., Kurmoo, M., Tung, C.-H., Sun, D., Zheng, L.-S., Chem. - Eur. J. 2016, 22, 17619;

4a) Troyano, J., Castillo, O., Amo-Ochoa, P., Fernandez-Moreira, V., Gomez-Garcia, C. J., Zamora, F., Delgado, S., J. Mater. Chem. C 2016, 4, 8545; b) Yam, V. W.-W., Wong, K. M.-C., Chem. Commun. 2011, 47, 11579; c) Toma, O., Mercier, N., Allain, M., Kassiba, A. A., Bellat, J.-P., Weber, G., Bezverkhyy, I., Inorg. Chem. 2015, 54, 8923.

5a) Kim, T. H., Shin, Y. W., Jung, J. H., Kim, J. S., Kim, J., Angew. Chem., Int. Ed. 2008, 47, 685; b) Shan, X.-C., Zhang, H.-B., Chen, L., Wu, M.-Y., Jiang, F.-L., Hong, M.-C., Cryst. Growth Des. 2013, 13, 1377; c) Zeng, G., Xing, S., Han, X., Xin, B., Yang, Y., Wang, X., Li, G., Shi, Z., Feng, S., RSC Adv. 2015, 5, 40792; d) Deshmukh, M. S., Yadav, A., Pant, R., Boomishankar, R., Inorg. Chem. 2015, 54, 1337.

6a) Zhao, Y., Hong, M., Liang, Y., Cao, R., Li, W., Weng, J., Lu, S., Chem. Commun. 2001, 11, 1020; b) He, J., Yang, C., Xu, Z., Zeller, M., Hunter, A. D., Lin, J., J. Solid State Chem. 2009, 182, 1821; c) Amo-Ochoa, P., Alexandre, S. S., Hribesh, S., Galindo, M. A., Castillo, O., Gómez-García, C. J., Pike, A. R., Soler, J. M., Houlton, A., Zamora, F., Inorg. Chem. 2013, 52, 5290; d) Guijarro, A., Castillo, O., Welte, L., Calzolari, A., Miguel, P. J. S., Gómez-García, C. J., Olea, D., di Felice, R., Gómez-Herrero, J., Zamora, F., Adv. Funct. Mater. 2010, $20,1451$.

7a) Zhang, Y., Xia, T., Yu, K. M., Zhang, F., Yang, H., Liu, B., An, Y., Yin, Y., Chen, X., ChemPlusChem 2014, 79, 559; b) Low, K.-H., Roy, V. A. L., Chui, S. S.-Y., Chan, S. L.-F., Che, C.-M., Chem. Commun. 2010, 46, 7328; c) Che, C.-M., Li, C.-H., Chui, S. S.-Y., Roy, V. A. L., Low, K.-H., Chem. - Eur. J. 2008, 14, 2965; d) Huang, X., Sheng, P., Tu, Z., Zhang, F., Wang, J., Geng, H., Zou, Y., Di, C.-A., Yi, Y., Sun, Y., Xu, W., Zhu, D., Nat. Commun. 2015, 6, 7408; e) Dahl, E. P., Carlson, R. M. K., Tkachenko, B. A., Fokin, A. A., Schreiner, P. R., Vailionis, A., Kim, T. R., Devereaux, T. P., Shen, Z., Melosh, N. A., Nat. Mater. 2017, 16, 349.

8a) Troyano, J., Perles, J., Amo-Ochoa, P., Martínez, J. I., Gimeno, M. C., Fernández-Moreira, V., Zamora, F., Delgado, S., Chem. - Eur. J. 2016, 22, 18027; b) Shan, X.-C., Jiang, F.-L., Yuan, D.-Q., Zhang, H.-B., Wu, M.-Y., Chen, L., Wei, J., Zhang, S.-Q., Pan, J., Hong, M.-C., Chem. Sci. 2013, 4, 1484.

9a) Zacher, D., Shekhah, O., Woll, C., Fischer, R. A., Chem. Soc. Rev. 2009, 38, 1418; b) Shekhah, O., Liu, J., Fischer, R. A., Woll, C., Chem. Soc. Rev. 2011, 40, 1081; c) Bétard, A., Fischer, R. A., Chem. Rev. 2012, 112, 1055.

10a) Song, Y., Fan, R., Wang, P., Wang, X., Gao, S., Du, X., Yang, Y., Luan, T., J. Mater. Chem. C 2015, 3, 6249; b) Chen, W., Fan, R., Zhang, H., Dong, Y., Wang, P., Yang, Y., Dalton Trans. 2017, 46, 4265; c) Zhang, 
H.-J., Fan, R.-Q., Wang, X.-M., Wang, P., Wang, Y.-L., Yang, Y.-L., Dalton Trans. 2015, 44, 2871; d) Shen, X., Yan, B., Dalton Trans. 2015, 44, 1875.

11 Rodriguez-San-Miguel, D., Amo-Ochoa, P., Zamora, F., Chem. Commun. 2016, 52, 4113.

12a) Rodenas, T., Luz, I., Prieto, G., Seoane, B., Miro, H., Corma, A., Kapteijn, F., Llabrés i Xamena, F. X., Gascon, J., Nat. Mater. 2015, 14, 48. b) Peng, Y., Li, Y. S., Ban, Y. J., Jin, H., Jiao, W. M., Liu, X. L., Yang, W. S., Science 2014, 346, 1356.

13a) Delgado, S., Sanz Miguel, P. J., Priego, J. L., Jiménez-Aparicio, R., Gómez-García, C. J., Zamora, F., Inorg. Chem. 2008, 47, 9128; b) Gallego, A., Castillo, O., Gomez-Garcia, C. J., Zamora, F., Delgado, S., Inorg. Chem. 2012, 51, 718; c) Troyano, J., Perles, J., Amo-Ochoa, P., Martinez, J. I., Zamora, F., Delgado, S., CrystEngComm 2014, 16, 8224; d) Troyano, J., Perles, J., Amo-Ochoa, P., Zamora, F., Delgado, S., CrystEngComm 2016, 18, 1809.

14a) Liu, J., Shao, C., Zhang, Y., Shi, G., Pan, S., Org. Biomol. Chem. 2014, 12, 2637; b) Luo, F., Pan, C., Cheng, J., Synlett 2012, 3, 357; c) Otera, J., Nishikido, J., Esterification: Methods, Reactions, and Applications, Wiley-VCH, Weinheim, Germany 2009.

15 Hassanein, K., Conesa-Egea, J., Delgado, S., Castillo, O., Benmansour, S., Martínez, J. I., Abellán, G., Gómez-García, C. J., Zamora, F., Amo-Ochoa, P., Chem. - Eur. J. 2015, 21, 17282.

16 Ares, P., Aguilar-Galindo, F., Rodríguez-San-Miguel, D., Aldave, D. A., Díaz-Tendero, S., Alcamí, M., Martín, F., Gómez-Herrero, J., Zamora, F., Adv. Mater. 2016, 28, 6332.

17a) Knotter, D. M., Blasse, G., Vliet, J. P. M., Koten, G., Inorg. Chem. 1992, 31, 2196; b) Knotter, D. M., Koten, G., Maanen, H. L., Grove, D. M., Spek, A. L., Angew. Chem., Int. Ed. 1989, 28, 341; c) Baumgartner, M., Schmalle, H., Dubler, E., Polyhedron 1990, 9, 1155.

18a) Eichhöfer, A., Buth, G., Lebedkin, S., Kühn, M., Weigend, F., Inorg. Chem. 2015, 54, 9413; b) Papanikolaou, P. A., Papadopoulos, A. G., Andreadou, E. G., Hatzidimitriou, A., Cox, P. J., Pantazaki, A. A., Aslanidis, P., New J. Chem. 2015, 39, 4830; c) Langer, R., Yadav, M., Weinert, B., Fenske, D., Fuhr, O., Eur. J. Inorg. Chem. 2013, 21, 3623.

19a) Yam, V. W.-W., Lo, K. K.-W., Wang, C.-R., Cheung, K.-K., J. Phys. Chem. A 1997, 101, 4666; b) Sabin, F., Ryu, C. K., Ford, P. C., Vogler, A., Inorg. Chem. 1992, 31, 1941.

20 Valeur, B., Berberan-Santos, M. N., Molecular Fluorescence: Principles and Applications, Wiley-VCH, Weinheim, Germany 2001, Ch. 4.

21a) DeCoste, J. B., Denny, J. M. S., Peterson, G. W., Mahle, J. J., Cohen, S. M., Chem. Sci. 2016, 7, 2711; b) Denny, M. S., Cohen, S. M., Angew. Chem., Int. Ed. 2015, 54, 9029; c) Bae, Y. J., Cho, E. S., Qiu, F., Sun, D. T., Williams, T. E., Urban, J. J., Queen, W. L., ACS Appl. Mater. Interfaces 2016, 8, 10098; d) Zhai, L., Zhang, W.W., Zuo, J.-L., Ren, X.-M., Dalton Trans. 2016, 45, 3372.

22 Paolo, G., Stefano, B., Nicola, B., Matteo, C., Roberto, C., Carlo, C., Davide, C., Guido, L. C., Matteo, C., Ismaila, D., Andrea Dal, C., Stefano de, G., Stefano, F., Guido, F., Ralph, G., Uwe, G., Christos, G., Anton, K., Michele, L., Layla, M.-S., Nicola, M., Francesco, M., Riccardo, M., Stefano, P., Alfredo, P., Lorenzo, P., Carlo, S., Sandro, S., Gabriele, S., Ari, P. S., Alexander, S., Paolo, U., Renata, M. W., J. Phys. Condens. Matter 2009, 21, 395502.

23 Perdew, J. P., Burke, K., Ernzerhof, M., Phys. Rev. Lett. 1997, 78, 1396.

24a) Rappe, A. M., Rabe, K. M., Kaxiras, E., Joannopoulos, J. D., Phys. Rev. B 1990, 41, 1227; b) Mounet, N., Marzari, N., Phys. Rev. B 2005, 71, 205214.

25 Chadi, D. J., Cohen, M. L., Phys. Rev. B 1973, 8, 5747.

26 Hybertsen, M. S., Louie, S. G., Phys. Rev. B 1986, 34, 5390.

27a) Albrecht, S., Reining, L., Del Sole, R., Onida, G., Phys. Rev. Lett. 1998, 80, 4510; b) Benedict, L. X., Shirley, E. L., Bohn, R. B., Phys. Rev. Lett. 1998, 80, 4514.

28 Marini, A., Hogan, C., Grüning, M., Varsano, D., Comput. Phys. Commun. 2009, 180, 1392.

29 Altomare, A., Cascarano, G., Giacovazzo, C., Guagliardi, A., J. Appl. Crystallogr. 1993, 26, 343. 
30 Sheldrick, G. M., SHELXL-97, Program for Crystal Structure Refinement, Universität Göttingen, 1997. 31 Farrugia, L., J. Appl. Crystallogr. 1999, 32, 837. 